\title{
Fast and slow myosins as markers of muscle injury
}

\author{
M Guerrero, ${ }^{1}$ M Guiu-Comadevall,, J A Cadefau, ${ }^{1} \mathrm{~J}$ Parra, ${ }^{1}$ R Balius, ${ }^{2}$ A Estruch, ${ }^{2}$ \\ G Rodas, ${ }^{3}$ J L Bedini, ${ }^{4}$ R Cussó ${ }^{1}$
}

${ }^{1}$ University of Barcelona, Barcelona, Spain; ${ }^{2}$ Centre d'Estudis d'Alt Rendiment Esportiu (CEARE), Barcelona, Spain; ${ }^{3}$ FC Barcelona (FCB). Barcelona, Spain; ${ }^{4}$ Hospital Clínic i Provincial de Barcelona Barcelona, Spain

Correspondence to: Professor R Cussó, Ciencias Fisiologicas I, Barcelona University, c/Casanova 143, 08036 Barcelona, Spain; mcusso@ub.edu

Accepted 9 August 2007

Published Online First

7 December 2007

\begin{abstract}
Objective: The diagnosis of muscular lesions suffered by athletes is usually made by clinical criteria combined with imaging of the lesion (ultrasonography and/or magnetic resonance) and blood tests to detect the presence of nonspecific muscle markers. This study was undertaken to evaluate injury to fast and slow-twitch fibres using specific muscle markers for these fibres.

Methods: Blood samples were obtained from 51 nonsports people and 38 sportsmen with skeletal muscle injury. Western blood analysis was performed to determine fast and slow myosin and creatine kinase (CK) levels. Skeletal muscle damage was diagnosed by physical examination, ultrasonography and magnetic resonance and biochemical markers.
\end{abstract}

Results: The imaging tests were found to be excellent for detecting and confirming grade II and III lesions. However, grade I lesions were often unconfirmed by these techniques. Grade I lesions have higher levels of fast myosin than slow myosin with a very small increase in CK levels. Grade II and III lesions have high values of both fast and slow myosin.

Conclusions: The evaluation of fast and slow myosin in the blood $48 \mathrm{~h}$ after the lesion occurs is a useful aid for the detection of type I lesions in particular, since fast myosin is an exclusive skeletal muscle marker. The correct diagnosis of grade I lesions can prevent progression of the injury in athletes undergoing continual training sessions and competitions, thus aiding sports physicians in their decision making.

Muscle is sensitive to the protocols of contraction and work to which it is submitted, since its structure is designed to support these protocols and to adapt to new situations of force. However, if the integrity is affected to a greater or lesser extent by overload, tears occur which are known as muscle lesions. These lesions can result in incapacity to continue exertion of the force.

Extenuating unaccustomed exercise and highforce eccentric action leads to skeletal muscle damage with changes in muscle structure and function. It induces damage to muscle fibre membranes, ${ }^{12}$ myofibrillar disruption ${ }^{3}$ and sarcoplasmic reticulum vacuolisation. ${ }^{4}$ Such exerciseinduced muscle damage activates a cascade of reactions that result in activated skeletal muscle protein metabolism. The protease calpain is activated immediately after exercise. Calpain initiates the metabolic turnover of myofibrillar proteins by releasing them from their filamentous structure. ${ }^{5}$ Although calpain does not degrade actin and myosin, it contributes to their release. ${ }^{6}$ This allows the detection of such proteins in peripheral blood after cleavage, using specific assays such as troponin I (TnI) and myosin heavy chains
(MHC). ${ }^{78}$ Sorichter et al ${ }^{9}$ described the features of an ideal marker of skeletal muscle fibre injury. One of these was that the marker should be absolutely muscle fibre-specific to allow reliable diagnosis of skeletal fibre type injury. None of the markers analysed by these authors is muscle type-specific.

The markers normally used include creatine kinase (CK), heart-fatty acid binding protein, myoglobin, TnI and $\alpha$-actin. ${ }^{10}$ However, in addition to not being totally specific for skeletal muscle, they reach a maximum value before $10 \mathrm{~h}$ have elapsed after the origin of the lesion and decrease to a considerable extent within $24 \mathrm{~h}$. Most lesions occur during holidays, so it is very easy for these 10-12 critical hours to pass before the patient is examined. New lesions are often not accompanied by pain, but a day later the markers of low molecular weight have degraded with no trace left in the serum. The troponins are proteins that are very specific in terms of fibre type; they are of low molecular weight but are susceptible to being rapidly proteolysed, which may explain their very short half-life in blood. ${ }^{11}$

Skeletal muscle is a heterogeneous tissue composed of fibre types I and II, the proportion of which varies with the type of muscle and even within the different regions of a particular type of muscle. ${ }^{12}$ Some of the contractile proteins have different isoforms depending on the type of fibre. One of these is myosin, which has different heavy and light isoforms depending on whether the fibre type is fast or slow. ${ }^{13}$

Myosin presents an ideal profile as a parameter to study and is directly assignable to the grade of the lesion since, because of its high molecular weight, its appearance in blood can only be explained by a fibre lesion. Fast myosin is characteristic of fast skeletal muscle only, while slow myosin is common to skeletal and cardiac muscle. The level of slow myosin in the blood has been measured by Schiaffino and Reggiani ${ }^{14}$ and reaches a maximum 48 and $72 \mathrm{~h}$ after the lesion.

The aim of this study is to evaluate muscle lesions using as markers fast and slow myosins present in the serum of athletes $48 \mathrm{~h}$ after suffering a lesion. The efficiency of these markers is compared with the detection of the lesion by ultrasonography (US), magnetic resonance (MR) and other traditional serum markers.

\section{METHODS}

\section{Materials}

The materials used in the study were monoclonal anti-myosin (skeletal, fast) clone My-32 (Sigma, Madrid, Spain), monoclonal anti-myosin (skeletal, slow) clone NOQ7.5.4D (Sigma), agarose (Sigma), protein A (Sigma) and loading buffer Nupage LDS sample buffer (Novex, California, USA). 


\section{Subjects}

Thirty-six sportsmen aged 18-25 years (athletes, jockeys, tennis players, football players, basketball players and pentathletes) who had suffered some pain and/or injury were studied. The control group comprised 51 non-sportsmen aged 18-55 years.

Muscle injuries were classified into three categories according to clinical findings: grade I (delayed onset muscle soreness and elongation, very small muscle tear); grade II (fibrillar disruption, moderate muscle tear); grade III (fibre disruption, evident muscle tear). Two $\mathrm{ml}$ of blood were obtained from the 51 controls and from the athletes $48 \mathrm{~h}$ after they had suffered the muscle problem. Serum was used for measurement of myosin levels.

\section{Treatment of the sample}

The blood samples were obtained in a Vacutainer tube and centrifuged at $2000 \mathrm{~g}$ at $4^{\circ} \mathrm{C}$ for $10 \mathrm{~min}$. The serum could be kept at $-80^{\circ} \mathrm{C}$ without any loss of myosin for 15 days. Serum protein was determined by the Bradford method. ${ }^{15}$ Myosin is present as a blood marker at a very low concentration compared with other serum proteins. It was therefore concentrated from the serum sample by immunoprecipitation with A protein linked to agaroseantibody. The pellet was resuspended with $15 \mu$ l loading buffer (60 mM HCl-Tris, 10\% glycerol, 2\% SDS, 5\% $\beta$-mercaptoethanol, $0.025 \%$ bromophenol blue, $\mathrm{pH} 6.8)$, centrifuged and warmed for $10 \mathrm{~min}$ to $70^{\circ} \mathrm{C}$. The sample (about $25 \mu \mathrm{l}$ ) was prepared to be carried out on Nupage Novex 3-8\% Tris-acetate gels and immunodetection. One or two fast myosin and slow myosin standards were loaded in every gel. Electrophoresis was run in $\mathrm{X}$ Cell SureLock Electrophoresis Cell (Invitrogen) at $150 \mathrm{~V}$ for $1 \mathrm{~h}$ at room temperature. The gel was cut into strips of $7 \times 1.2 \mathrm{~cm}$. The gel for immunoblot analyses was transferred to a PVDF sequencing membrane (Immobilon PSQ Millipore) at $33 \mathrm{~V}$ for $70 \mathrm{~min}$ at room temperature.

The blots were treated with SuperBlocking buffer in PBS (Pierce) at $0.01 \%$ to Tween 20 for $1.5 \mathrm{~h}$ at room temperature. One gel was reacted with 1:90000 anti-myosin fast monoclonal antibody and the other with 1:150 000 anti-myosin slow monoclonal antibody. Membranes were washed with $0.01 \%$ Tween 20 at PBS six times for $5 \mathrm{~min}$ and incubated with horseradish peroxidase conjugated rabbit anti-mouse IgG (1:90 000) for $1 \mathrm{~h}$ at room temperature, followed by additional washes (six times for $5 \mathrm{~min}$ in $0.01 \%$ Tween 20 at PBS). Each strip was mixed with $80 \mu \mathrm{l}$ of a mix (1:1) of Ultra Supersignal for 5 min. Proteins were visualised by enhanced chemiluminescence (SuperSignal West Dura Trial Kit, Pierce, Rockford, Illinois, USA). After drying, the strips were printed on the Hyperfilm TM ECL for $10 \mathrm{~min}$. This process was prepared with two samples, one for detecting fast myosin and the other for slow myosin.

The films were scanned with a Hewlett Packard Scanjet 5200C and quantification was done with Quantity One 1-D (BioRad, Hercules, California, USA).

\section{Fast and slow myosin standards}

The protein standards were prepared from fast and slow rabbit muscle (tibialis anterior for fast fibres and soleus for slow fibres). Purified myofibrils were obtained according to the method described by Hasten et al. ${ }^{16}$ After carrying out this process, myofibril suspensions of about $1 \mathrm{mg} / \mathrm{ml}$ of protein were obtained. The suspension was denatured with the loading buffer $1: 1 \mathrm{v} / \mathrm{v}$ for $2 \mathrm{~min}$ at $100^{\circ} \mathrm{C}$. $70 \mu \mathrm{g}$ of protein was applied to an acrylamide gel $(7.5 \% \mathrm{~T}, 2.5 \% \mathrm{C})$ to separate the proteins. The electrophoresis was run for $75 \mathrm{~min}$ at $150 \mathrm{~V}$. The presence of myosin was localised by staining a gel with Coomassie Blue G-250 R-250 (BioRad). The bands from an undyed gel were cut and electroluted with a commercial electroluter (BioRad Model 422) during $60 \mathrm{~mA}, 5 \mathrm{~h}$ with the electrolution buffer $(25 \mathrm{mM} \mathrm{HCl}$-tris, $192 \mathrm{mM}$ glycine, $0.1 \%$ SDS, $\mathrm{pH}$ 6.8). We obtained $0.93 \mu \mathrm{g} / \mu \mathrm{l}$ fast myosin and $1.55 \mu \mathrm{g} / \mu \mathrm{l}$ of slow myosin. The myosins were diluted with $10 \mathrm{mM} \mathrm{HCl}-$ Tris, $300 \mathrm{mM} \mathrm{NaCl}, 2 \mathrm{mM}$ EDTA at pH 6.8. Standards were kept in fractions of $50 \mu \mathrm{l}$ at $-30^{\circ} \mathrm{C}$.

\section{Measurement of enzymatic activities}

CK was determined by a Technicon DAX System autoanalyser according to the method of Szasz et al. ${ }^{17}$

\section{Imaging evaluation}

Echography was carried out at the Centre d'Estudis d'Alt Rendiment Esportiu (CEARE) and in the ultrasonographic department of the FIATC Clinic using Toshiba Medical System ultrasonography equipment with a multifrequency probe (JustVision in CEARE, PowerVision in FIATC). Magnetic resonance studies were done at the department of magnetic resonance of the Corachán Clinic using a Siemens Symphony device (1.5 TESS).

Both types of soundings gave results which increased in direct proportion with the grade of the lesion. In grade I lesions US usually shows the lesion (haematic suffusion and defect of some
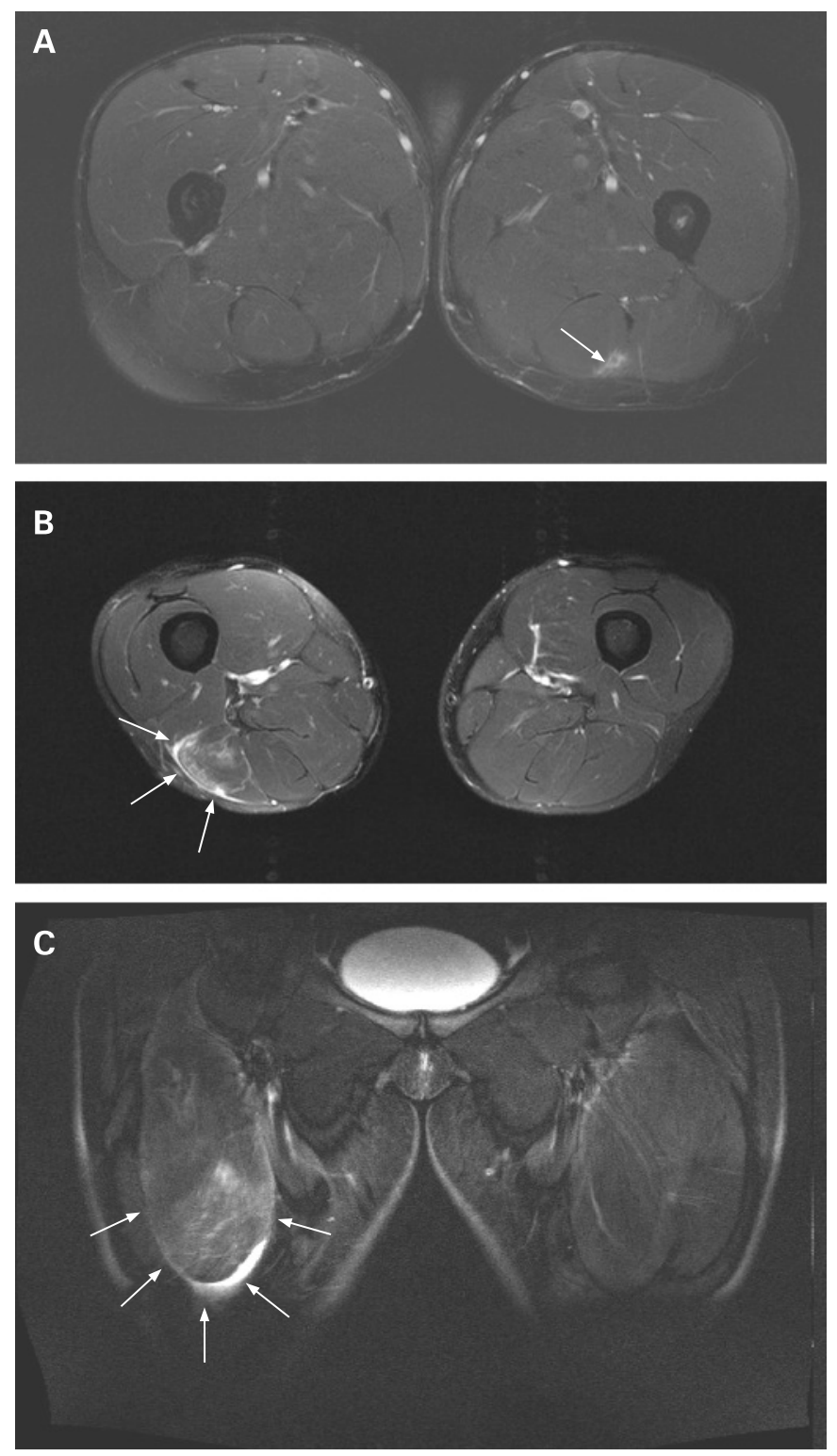

Figure 1 Magnetic resonance images of different grades of muscle lesion: (A) grade I lesion; (B) grade II lesion; (C) grade III lesion. 

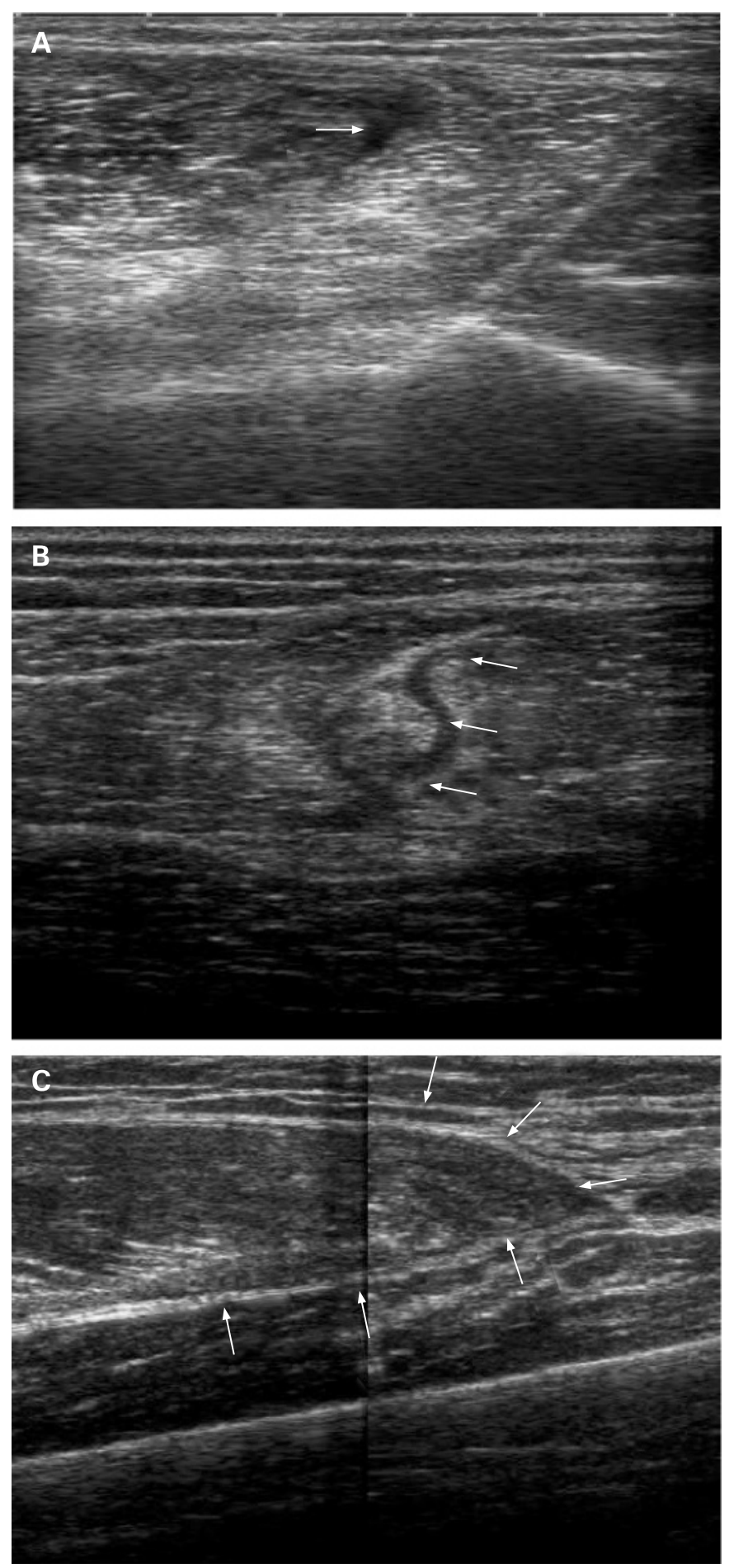

Figure 2 Ultrasonographic appearance of different grades of muscle lesion: (A) grade I lesion; (B) grade II lesion; (C) grade III lesion.

fibres) 2-3 days after the accident while MR shows muscular oedema from the time the lesion occurs. In grade II lesions both US and MR show oedema and fibrillar defects, and grade III lesions show a greater defect associated with haematoma and muscle. Both US and MR show the evolution of the lesion, observing how the oedema disappears and fibrillar repair occurs.

\section{Statistical analysis}

The levels of the each marker in controls and subjects with different grades of injury were compared by analysis of variance (ANOVA); $p$ values of $<0.05$ were considered significant.

\section{RESULTS}

\section{MR images}

Figure 1 shows MR images of three different grades of muscle lesion. Figure $1 \mathrm{~A}$ is an axial view of a grade I lesion in the upper part of the posterior side of the right thigh showing a zone of muscle oedema (signal increase) transduced by a recent tear of the lesion in the medial-distal part of the posterior side of the left thigh showing an area of oedema (signal increase) and fibrillar defect transduced by a recent lesion in the long head of the biceps femoris (arrows). In the coronal view of a grade III lesion of the distal part of the anterior side of the thigh shown in fig 1C, a large area of oedema (signal increase) and extensive fibrillar defect of the rectus femoris can be seen in the distal part (arrows).

\section{US images}

Figure 2 shows the US appearance of the lesions shown in fig 1 Figure $2 \mathrm{~A}$ is a transverse section of a grade I lesion showing the area of fibrillar defect located between the biceps femoris and the semitendinous. The transverse section of a grade II lesion shown in fig $2 \mathrm{~B}$ shows the most extensive area of the fibrillar defect and haematic suffusion in the long head of the biceps femoris. The US appearance of a longitudinal section of a grade III lesion in fig 2C shows complete muscle defect of the rectus femoris (arrows).

\section{Clinical diagnosis, marker enzymes and myosin in normal and injured muscles}

Table 1 shows normal serum values of the control group and of the athletes with different grades of muscle lesions. Our results indicate that, in the normal state, the concentration of fast and slow myosins in blood did not exceed $1000 \mu \mathrm{g} / \mathrm{ml}$ fast myosin and $2000 \mu \mathrm{g} / \mathrm{ml}$ slow myosin, showing a fast/slow ratio of 0.3 . The patients diagnosed with grade I lesions, which were not imaged by US or MR, had high levels of fast myosin (greater than slow myosin), showing a fast/slow ratio of $>2$. CK levels were almost within the limits of normality. In grade II and III lesions, which were diagnosed by US and MR, an increase in both fast and slow myosins was observed with a fast/slow ratio near to 1 . The concentration of slow myosin compared with fast myosin increased in direct proportion to the severity of the lesion. CK levels also increased in the same direction as the particularly good marker for grade II and III lesions.

\section{DISCUSSION}

Human muscles are made up of a mixture of slow and fast fibres with approximately $50 \%$ of each. This is different from animals, some of which have $90 \%$ of fast fibres and some up to $90 \%$ of slow fibres. The vastus lateralis of young Caucasian athletes aged 15-18 years has $36.5 \%$ slow-type fibres and $63.5 \%$ fast-type fibres and, of these, $52.3 \%$ are type IIa, $8.1 \%$ type $\mathrm{IIb}$ and $3.1 \%$ type IIc. ${ }^{18}$ The existence of mixed muscles in humans means that lesions allow the entrance of both slow and fast myosins into the blood. However, due to the fact that resistance to lesions and to fatigue in the two types of fibres is not the same, the level of slow or fast myosin heavy chain (MHC) in the blood depends on the type of fibre damaged. In general, fast fibres are more easily fatigued and are more sensitive to the lesion. We can therefore expect that fast fibres release fast $\mathrm{MHC}$ before slow fibres in the face of less intense exercise. Slow MHCs will flow under more fatiguing conditions and their presence in the blood will probably indicate a more important lesion.

On the other hand, the presence of fast MHC in blood signals the fact that only skeletal muscle is affected and thus constitutes an absolutely specific marker. The presence of slow biceps femoris (arrows). Figure $1 \mathrm{~B}$ is an axial view of a grade II severity of the muscle lesion, which suggests that it is a 
Table 1 Comparison of results obtained by different methods for diagnosis of muscle injuries

\begin{tabular}{llllllll}
\hline Diagnosis & No of samples & US & MR & CK (U/I) & Fast myosin $(\mu \mathrm{g} / \mathbf{l})$ & Slow myocin $(\boldsymbol{\mu g} / \mathbf{l})$ & Fast/slow ratio \\
\hline Normal & 51 & - & - & $102(8)$ & $625(62)$ & $1535(166)$ & 0.3 \\
Grade I & 12 & $(-)$ o (+) & - & $202(22)$ & $2880(159)$ & $1281(197)$ & 2.2 \\
Grade II & 16 & ++ & ++ & $482(47)$ & $3432(402)$ & $3722(700)$ & 0.9 \\
Grade III & 10 & +++ & +++ & $739(245)$ & $8055(2200)$ & $6518(124)$ & 1.2 \\
\hline
\end{tabular}

Data are expressed as mean (SE).

US, ultrasonography; MR, magnetic resonance; CK, creatine kinase.

Statistical ANOVA was found to be very significant for every parameter $(p<0.001)$.

MHC could indicate the presence of a lesion in the skeletal and/ or heart muscle. However, given the fact that the subjects of this study were athletes in whom a cardiac lesion is ruled out, the detection of slow MHC in blood would act as a marker of a slow fibre lesion with the consequences that this information would be able to contribute.

We have developed a method to detect myosins in blood based on specific recognition by fast and slow myosin antibodies. We studied a group of athletes involved in different sports who presented with muscle pain. The patients underwent a medical examination, US, MR and blood tests including measurement of CK levels (used as a usual muscle marker) and slow and fast myosins. We also studied 51 people who did not practise any sport either sporadically or for pleasure and who were categorised as normal.

Our results indicate that, $48 \mathrm{~h}$ after the onset of the muscle problem, CK activity showed a small increase in grade I lesions. Only fast myosin is a marker with very high values, suggesting that grade I lesions are mainly produced in type II fibres. The results of US and MR in grade I lesions are confusing in some cases, with negative or positive results that fail to assure total recognition of the lesion. US and MR in grade II and grade III lesions were highly effective in detecting the lesions.

In grade II lesions measurement of the serum markers showed an increase in CK activity, with the greatest increases being those of both types of myosin, reaching up to 10 times the normal value in some cases. Grade III lesions were well detected by CK activity and also by both types of myosin.

We conclude that the use of fast myosin provides a highly sensitive marker for grade I lesions, at least equal to MR and better than US and clinical diagnosis. Fast myosin is a totally specific marker for skeletal muscle, a property not shared by any of the markers currently in use such as CK and myoglobins. Myosin also has the advantage of being more sensitive and more stable in blood, since its maximum level is reached $48 \mathrm{~h}$ after the lesion and it remains in the blood for longer so that it is easier to use in diagnoses not carried out immediately and can be used to follow the development of the muscle lesion. We therefore conclude that the determination of fast and slow myosins is a useful aid in the diagnosis of muscle lesions, especially for those that are difficult to detect by other procedures.

Acknowledgements: The authors thank the volunteers who participated in the study and the CEARE and the IDIBAPS of the Faculty of Medicine for their cooperation.

Funding: This study was financed mainly by two grants from the Consell Català de I'Esport (Catalan Sports Council of the Generalitat of Catalunya) and a small collaboration from the Consejo Superior de Deportes (Higher Council for Sports of the $\mathrm{MEC}$ ) and from the FISS of the Instituto Carlos III (Red de Centros RCMN-C03708).

Competing interests: None.

Ethics approval: This study was approved by the ethics committee of the University of Barcelona and the ethics committee of the Hospital Clinic i Provincial of Barcelona.

\section{REFERENCES}

1. Armstrong RB, Ogilvi RW, Schwane JA. Eccentric exercise-induced injury to rat skeletal muscle. J Appl Physiol 1983;436:735-41.

2. Newman DJ, Jones DA, Ghosh G, et al. Muscle fatigue and pain after eccentric contractions at long and short length. Clin Sci 1988;74:553-7.

3. Friden J, Lieber RL. Structural and mechanical bases of exercise-induced muscle injury. Med Sci Sports Exerc 1992;24:521-30.

4. Frias JA, Cadefau JA, Prats $C$, et al. Disturbances of the sarcoplasmic reticulum and transverse tubular system in 24-h electrostimulated skeletal muscle. Biochem Biophys Acta 2005;1668:64-74.

5. Belcastro AN, Gilchrist JS, Scrubb JA, et al. Calcium-supported calpain degradation rates for cardiac myfibrils in diabetes. Sulfhydryl and hydrophobic interactions. Mol Cell Biochem 1994;15:51-60.

6. Goll DE, Thompson VH, Taylor RG, et al. Is calpain activity regulated by membranes and autolysis or by calcium and calpastatin? BioEssays 1992;14:549-56.

7. Sorichter S, Mair J, Koller A, et al. Skeletal troponin I as a marker of exerciseinduced muscle damage. J Appl Physiol 1997;83:1076-82.

8. Sorichter S, Mair J, Koller A, et al. Skeletal muscle troponin I release and magnetic resonance imaging signal intensity changes after eccentric exercise-induced skeletal muscle injury. Clin Chim Acta 1997;262:139-46.

9. Sorichter S, Puschendorf B, Mair J. Skeletal muscle injury induced by eccentric muscle action: muscle proteins as markers of muscle fiber injury. Exerc Immunol Rev 1999:5:5-21.

10. Martinez A, Marchal JA, Rodriguez F, et al. Role of $\alpha$-actin in muscle damage of injured athletes in comparison with traditional markers. Br J Sports Med 2007:41:442-6.

11. Ebbeling CB, Clarkson PM. Exercise-induced muscle damage and adaptation. Sports Med 1989;7:207-34.

12. Lexell J, Henrikson-Larsen K, Sjostrom M. Distribution of different fibre types in human skeletal muscles. 2. A study of cross-sections of whole $\mathrm{m}$. vastus lateralis. Acta Physiol Scand 1983;117:115-22.

13. Pette D, Staron RS. Myosin isoforms, muscle fiber types, and transitions. Microsc Res Tech 2000;50:500-9.

14. Schiaffino S, Reggiani C. Molecular diversity of miofibrillar proteins: gene regulation and funtional significance. Physiol Rev 1996;76:371-423.

15. Bradford MM. A rapid and sensitive method for the quantification of microgram quantities of protein utilising the principle of protein-dye binding. Anal Biochem 1976; 72:248-54.

16. Hasten DL, Morris GS, Ramanadham S, et al. Isolation of human skeletal muscle myosin heavy chain and actin for measurement of fractional synthesis rates. Am J Physiol Endocrinol Metab 1998;275:E1092-9.

17. Szasz G, Gruber W, Bernt E. Creatine kinase in serum. Determination of optimun reaction conditions. Clin Chem 1976;22:650-6.

18. Cadefau JA, Casademont J, Grau JM, et al. Biochemical and histochemical adaptation to sprint training in young athletes. Acta Physiol Scand 1990;140:341-51.

\section{Commentary}

The detection and diagnosis of muscle lesions in sportsmen and sportswomen is usually performed by medical examination, imaging techniques and laboratory tests for blood analysis. Imaging techniques are excellent for detecting and confirming grade II and grade III lesions but they give ambiguous results in some cases of grade I lesions. On the other hand, laboratory tests for blood analysis routinely determine creatine kinase and myoglobin as markers for injury. However, the cytosolic proteins do not necessarily reflect the amount of structural damage suffered by the muscle fibre. Hence, the potential of structurally-bound proteins as markers of muscle damage needs to be investigated. The authors show that fast and slow myosins are good markers for muscle lesions; in addition to their muscle fibre specificity, favourable time course for muscle release and stability in blood, serum levels of fast myosin provide a very sensitive marker for grade I lesions.

A Megias Universidad Complutense, Madrid, Spain; amegias@solea.quim.ucm.es 
20. Thomas CD, Feik SA, Clement JG. Regional variation of intracortical porosity in the midshaft of the human femur: age and sex differences. J Anat 2005;206:115-25.

21. Goldman HM, Thomas CD, Clement JG, et al. Relationships among microstructural properties of bone at the human midshaft femur. J Anat 2005:206:127-39.

22. Drapeau MS, Streeter MA. Modeling and remodeling responses to normal loading in the human lower limb. Am J Phys Anthropol 2006;129:403-9.

23. Skedros JG, Mason MW, Bloebaum RD. Differences in osteonal micromorphology between tensile and compressive cortices of a bending skeletal system: indications of potential strain-specific differences in bone microstructure. Anat Rec 1994;239:405-13.

24. Nonaka K, Fukuda S, Aoki K, et al. Regional distinctions in cortical bone mineral density measured by POCT can predict alterations in material property at the tibial diaphysis of the cynomolgus monkey. Bone 2006;38:265-72.

25. Lai YM, Qin L, Hung VW, et al. Regional differences in cortical bone mineral density in the weight-bearing long bone shaft - a pQCT study. Bone 2005;36:465-71.

26. Roldan EJ, Capiglioni R, Cointry CR, et al. Postmenopausal changes in the distribution of the volumetric BMD of cortical bone. A pOCT study of the human leg. J Musculoskelet Neuronal Interact 2001;2:157-62.

27. Mackelvie KJ, McKay HA, Khan KM, et al. Lifestyle risk factors for osteoporosis in Asian and Caucasian girls. Med Sci Sports Exerc 2001;33:1818-24.

28. Kontulainen SA, Macdonald HM, Khan KM, et al. Examining bone surfaces across puberty: a 20-month pQCT trial. J Bone Miner Res 2005:20:1202-7.

29. Crocker PR, Bailey DA, Faulkner RA, et al. Measuring general levels of physical activity: preliminary evidence for the physical activity questionnaire for older children. Med Sci Sports Exerc 1997;29:1344-9.

30. Kowalski KC, Crocker PR, Faulkner RA. Validation of the physical activity questionnaire for older children. Pediatr Exerc Sci 1997:9:174-86.

31. Baxter-Jones AD, Mirwald RL, McKay HA, et al. A longitudinal analysis of sex differences in bone mineral accrual in healthy 8-19-year-old boys and girls. Ann Hum Biol 2003;30:160-75.

32. Peterman MM, Hamel AJ, Cavanagh PR, et al. In vitro modeling of human tibial strains during exercise in micro-gravity. J Biomech 2001;34:693-8.

33. Sonoda N, Chosa E, Totoribe K, et al. Biomechanical analysis for stress fractures of the anterior middle third of the tibia in athletes: nonlinear analysis using a threedimensional finite element method. J Orthop Sci 2003:8:505-13.

34. Binkley TL, Specker BL, Wittig TA. Centile curves for bone densitometry measurements in healthy males and females ages 5-22 yr. J Clin Densitom 2002;5:343-53.

35. Lorentzon M, Mellstrom D, Ohlsson C. Age of attainment of peak bone mass is site specific in Swedish men - the GOOD study. J Bone Miner Res 2005;20:1223-7.
36. Wang $\mathbf{0}$, Nicholson PH, Suuriniemi M, et al. Relationship of sex hormones to bone geometric properties and mineral density in early pubertal girls. J Clin Endocrinol Metab 2004;89:1698-703.

37. Moyer-Mileur L, Xie B, Ball S, et al. Predictors of bone mass by peripheral quantitative computed tomography in early adolescent girls. J Clin Densitom 2001:4:313-23.

38. Wang $\mathbf{0}$, Alen $\mathrm{M}$, Nicholson $\mathrm{P}$, et al. Growth patterns at distal radius and tibial shaft in pubertal girls: a 2-year longitudinal study. J Bone Miner Res 2005;20:954-61.

39. Lorentzon M, Mellstrom D, Ohlsson C. Association of amount of physical activity with cortical bone size and trabecular volumetric BMD in young adult men: the GOOD study. J Bone Miner Res 2005;20:1936-43.

40. Nikander R, Sievanen H, Uusi-Rasi K, et al. Loading modalities and bone structures at nonweight-bearing upper extremity and weight-bearing lower extremity: a pOCT study of adult female athletes. Bone 2006;39:886-94.

41. Heinonen A, Sievanen $\mathrm{H}$, Kyrolainen $\mathrm{H}$, et al. Mineral mass, size, and estimated mechanical strength of triple jumpers' lower limb. Bone 2001;29:279-85.

42. Heinonen A, Sievanen $H$, Kannus $P$, et al. Site-specific skeletal response to longterm weight training seems to be attributable to principal loading modality: a pQCT study of female weightlifters. Calcif Tissue Int 2002;70:469-74.

43. Haapasalo $\mathbf{H}$, Kontulainen $\mathrm{S}$, Sievanen $\mathrm{H}$, et al. Exercise-induced bone gain is due to enlargement in bone size without a change in volumetric bone density: a periphera quantitative computed tomography study of the upper arms of male tennis players. Bone 2000:27:351-7.

44. Kontulainen S, Sievanen $\mathrm{H}$, Kannus $\mathrm{P}$, et al. Effect of long-term impact-loading on mass, size, and estimated strength of humerus and radius of female racquet-sports players: a peripheral quantitative computed tomography study between young and old starters and controls. J Bone Miner Res 2002;17:2281-9.

45. Specker B, Binkley T, Fahrenwald N. Rural versus nonrural differences in BMC, volumetric BMD, and bone size: a population-based cross-sectional study. Bone 2004;35:1389-98.

46. Hangartner TN. Thresholding technique for accurate analysis of density and geometry in QCT, pQCT and microCT images. J Musculoskelet Neuronal Interact 2007; 7:9-16.

47. Ward KA, Adams JE, Hangartner TN. Recommendations for thresholds for cortica bone geometry and density measurement by peripheral quantitative computed tomography. Calcif Tissue Int 2005; 77:275-80.

48. Bousson V, Bergot C, Meunier A, et al. CT of the middiaphyseal femur: cortical bone mineral density and relation to porosity. Radiology 2000;217:179-87.

\section{CORRECTION}

doi: 10.1136/bjsm.2007.037945corr1

There was an error in the article by Guerrero et al published in the July issue of the journal (Guerrero M, Guiu-Comadevall M, Cadefau JA, et al. Fast and slow myosins as markers of muscle injury. Br J Sports Med 2008;42:581-4). Table 1 was omitted from the article. The table is reproduced online at http://bjsm.bmj.com/supplemental/. 